\title{
Consumo e digestibilidade aparente de silagens de sorgo em diferentes estádios de maturação
}

[Intake and apparent digestibility of sorghum silages at different maturation stages]

\author{
F.S. Machado ${ }^{1}$, N.M. Rodríguez ${ }^{2}$, L.C. Gonçalves ${ }^{2}$, J.A.S. Rodrigues ${ }^{3}$, M.N. Ribas ${ }^{2}$, \\ F.P. Pôssas ${ }^{2}$, R. Guimarães Júnior ${ }^{4}$, D.G. Jayme ${ }^{2}$, L.G.R. Pereira ${ }^{1}$ \\ ${ }^{1}$ Embrapa Gado de Leite - CNPGL \\ Rua Eugênio do Nascimento, 610 - Bairro Dom Bosco \\ 36038-330 - Juiz de Fora, MG \\ ${ }^{2}$ Universidade Federal de Minas Gerais - Belo Horizonte, MG \\ ${ }^{3}$ Embrapa Milho e Sorgo - Sete Lagoas, MG \\ ${ }^{4}$ Embrapa Cerrados - Fortaleza, CE
}

\begin{abstract}
RESUMO
Avaliaram-se o consumo e a digestibilidade aparente, em ovinos, das silagens dos híbridos de sorgo BRS 610, BR 700 e BRS 655 colhidos em três estádios de maturação dos grãos: leitoso, pastoso e farináceo. Os valores de consumo da matéria seca, em gramas por quilograma de unidade de tamanho metabólico (CMS-UTM), variaram de 45,90g/UTM/dia a 59,99g/UTM/dia e não diferiram com o avanço do estádio de maturação para todos os híbridos $(\mathrm{P}>0,05)$. No estádio pastoso, o BRS 655 apresentou menor CMS-UTM em relação aos demais híbridos $(\mathrm{P}<0,05)$, que foram semelhantes entre si $(\mathrm{P}>0,05)$. Foi observado menor consumo de proteína digestível para os híbridos com tanino, BR 700 e BRS 655, em relação ao BRS $610(\mathrm{P}<0,05)$ nos estádios pastoso e farináceo. Todos os tratamentos apresentaram balanço de nitrogênio levemente positivo, com valores entre $0,02 \mathrm{~g} / \mathrm{UTM} / \mathrm{dia}$ e $0,20 \mathrm{~g} / \mathrm{UTM} / \mathrm{dia}$. Não houve diferenças nos valores de digestibilidade da fibra entre os híbridos com tanino, BR 700 e BRS 655, e sem tanino, BRS 610. Recomenda-se a utilização da silagem do híbrido BRS 610, colhida no estádio pastoso. Os híbridos BRS 655 e BR 700 devem ser colhidos no estádio leitoso.
\end{abstract}

Palavras-chave: ruminante, sorghum bicolor, valor nutricional

\section{ABSTRACT}

The intake and apparent digestibility of the silages of the sorghum hybrids BRS 610, BR 700 and BRS 655 harvested at three maturation stages of milk, soft dough and floury grains by sheep were evaluated. The dry matter intake, in grams per metabolic weight (DMI-MW), ranged from 45.90 to $59.99 \mathrm{~g} / \mathrm{MW} / \mathrm{day}$ and didn't change with maturity $(P>0.05)$ for all the hybrids. At the soft dough stage, BRS 655 presented lower DMI-MW $(P<0.05)$ than the other hybrids, which were similar $(P>0.05)$. The hybrids with tannin $(B R 700$ and BRS 655) had lower intakes of digestible protein than the BRS 610 at the soft dough and floury stages $(P<0.05)$. All the treatments showed slight positive nitrogen balance which varied from $0.02 \mathrm{~g} / \mathrm{MW} / \mathrm{d}$ to $0.20 \mathrm{~g} / \mathrm{MW} / \mathrm{d}$. No differences were observed in fiber digestibility among hybrids with tannins (BR 700 e BRS 655) and without tannins (BRS 610). The use of BRS 610 is recommended and should be ensilaged at soft dough stage. The hybrids BR 655 and BR 700 should be harvested at milk stage.

Keywords: ruminant, nutritional value, sorghum bicolor

\section{INTRODUÇÃO}

A intensificação dos processos produtivos na pecuária de corte e de leite nacional promoveu aumento das necessidades quantitativas e

Recebido em 21 de julho de 2010

Aceito em 13 de julho de 2011

E-mail: fernanda@cnpgl.embrapa.br

Pesquisa financiada pelo CNPq e FAPEMIG qualitativas de alimentos para os animais, principalmente nos períodos de escassez de pastagens. Nesse aspecto, a produção de silagem de alta qualidade torna-se uma alternativa viável à manutenção dos sistemas de forrageamento, por restringir o período de carência alimentar e 
contribuir para a melhora dos índices zootécnicos do rebanho bovino nacional.

O sorgo mostra grande flexibilidade para ser utilizado em diferentes sistemas de produção de forragem: apresenta maior amplitude de época de plantio, custo de produção menor, possibilidade de aproveitamento da rebrota e, por ser mais resistente ao déficit hídrico e às altas temperaturas, pode ser cultivado com vantagens em regiões inadequadas para o cultivo de milho. Dessa forma, em regiões áridas e semiáridas, o sorgo tem sido cultivado como primeira cultura, já em regiões com melhor distribuição de chuvas, essa cultura vem apresentando boa adaptação ao cultivo de safrinha (Pedreira et al., 2003).

$\mathrm{Na}$ avaliação do valor nutritivo dos alimentos, a simples determinação da composição química não é suficiente, devendo ser considerados também os efeitos dos processos de consumo, digestão, absorção e metabolismo animal. Conforme Van Soest (1994), os alimentos não são iguais em sua capacidade de dar suporte às funções de mantença, crescimento, reprodução e lactação. Além das características peculiares das frações nutritivas constituintes, os alimentos consumidos pelos ruminantes são transformados pelos microrganismos ruminais, impedindo a predição do desempenho somente a partir dos componentes dietéticos (Russell et al.,1992).

Os ensaios in vivo envolvendo produção animal e digestibilidade são os métodos mais precisos para determinar o valor nutricional dos alimentos. A avaliação da digestibilidade de uma forrageira torna-se importante, baseada na necessidade de se comparar diferentes forrageiras e cultivares, considerando-se que as mais digestíveis apresentarão melhor retorno econômico/produtivo pelos animais que as consumiram (Molina et al., 2002).

O objetivo deste trabalho foi comparar as silagens dos híbridos de sorgo BRS 610, BR 700 e BRS 655, bem como determinar o melhor momento de colheita para produção de silagem.

\section{MATERIAL E MÉTODOS}

Três híbridos de sorgo (BRS 610, BR 700 e BRS 655) foram plantados nas dependências da EMBRAPA Milho e Sorgo, localizada no município de Sete Lagoas, região metalúrgica de Minas Gerais. Cada híbrido de sorgo foi colhido em três idades de corte com diferentes estádios de maturação dos grãos: leitoso, pastoso e farináceo. A composição química das silagens utilizadas está apresentada na Tab. 1 .

Tabela 1. Composição química (\% na MS) das silagens dos híbridos de sorgo em três estádios de maturação

\begin{tabular}{lccccccc}
\hline \multirow{2}{*}{ Híbridos } & \multicolumn{7}{c}{ Parâmetros } \\
\cline { 2 - 7 } & MS (\%) & PB (\%) & FDN (\%) & FDA (\%) & CEL (\%) & HCEL (\%) & LIG (\%) \\
\hline BRS 610 & 22,31 & 6,89 & 61,57 & 36,20 & 30,99 & 25,37 & 5,21 \\
BR 700 & 29,45 & 6,69 & 60,29 & 33,40 & 27,37 & 26,89 & 6,03 \\
BRS 655 & 22,57 & 6,42 & 63,66 & 37,72 & 31,83 & 25,94 & 5,89 \\
\hline \multicolumn{7}{c}{ Pastoso } \\
\hline BRS 610 & 23,89 & 6,67 & 59,54 & 35,29 & 29,39 & 24,25 & 5,90 \\
BR 700 & 32,12 & 6,21 & 61,38 & 34,63 & 28,23 & 26,75 & 6,40 \\
BRS 655 & 25,03 & 6,07 & 63,85 & 35,27 & 29,92 & 28,58 & 5,35 \\
\hline \multicolumn{7}{c}{ Farináceo } \\
\hline BRS 610 & 27,01 & 6,38 & 54,99 & 31,19 & 25,86 & 23,80 & 5,33 \\
BR 700 & 38,06 & 6,13 & 63,90 & 34,96 & 29,16 & 28,95 & 5,80 \\
BRS 655 & 25,05 & 6,76 & 61,35 & 33,51 & 27,20 & 27,85 & 6,31 \\
\hline
\end{tabular}

MS: matéria seca; PB: proteína bruta; FDN: fibra em detergente neutro; FDA: fibra em detergente ácido; CEL: celulose; HCEL: hemicelulose; LIG: lignina.

No ensaio de consumo e digestibilidade aparente, foram utilizados 45 carneiros adultos, machos, castrados, sem raça definida, com peso médio de $47,5 \mathrm{~kg}$. Os animais foram pesados, vermifugados e casqueados antes de serem alojados, individualmente, em gaiolas metabólicas. A quantidade de silagem de sorgo fornecida foi calculada para proporcionar consumo de 
mantença - 60 a 80 gramas de matéria seca por quilo de unidade de tamanho metabólico -, sendo oferecida duas vezes ao dia às $6 \mathrm{~h}$ e às $17 \mathrm{~h}$ e 30min. Os animais receberam água e mistura mineral ad libitum durante todo o período experimental.

Após 20 dias de adaptação às dietas, seguiu-se o período de cinco dias de coleta, quando foi foram realizadas a pesagem e a amostragem individuais (10\% do total mensurado) da silagem oferecida, sobras no cocho, fezes e urina. Para evitar a perda de nitrogênio da urina, diariamente, foram adicionados $100 \mathrm{~mL}$ de $\mathrm{HCl} 2 \mathrm{~N}$ aos baldes coletores.

Nas amostras de silagens, sobras e fezes, foram determinados os teores de matéria seca (MS) em estufa a $105^{\circ} \mathrm{C}$-, proteína bruta $(\mathrm{PB})$ - pelo método de Kjeldahl (Official..., 2000) -, e frações fibrosas - pelo método sequencial de Van Soest et al. (1991). As amostras de urina foram analisadas para determinação do nitrogênio total, pelo método de Kjeldahl (Official..., 2000). A avaliação do consumo de matéria seca (CMS) das silagens foi determinada pela diferença entre a quantidade de alimento fornecido e a quantidade de sobras no cocho. Os valores de digestibilidade da matéria seca, da proteína bruta e das frações fibrosas foram obtidos conforme metodologia utilizada por Maynard et al. (1984). O delineamento experimental utilizado foi inteiramente ao acaso, em desenho fatorial $3 \times 3$, sendo três híbridos e três estádios de maturação (idades de corte) e cinco repetições (carneiros). Os dados obtidos foram submetidos à análise de variância utilizando-se o pacote estatístico Sistema... (2007), e as médias comparadas pelo teste SNK, a $5 \%$ de probabilidade $(\mathrm{P}<0,05)$.

\section{RESULTADOS E DISCUSSÃO}

Os valores médios de consumo de matéria seca por unidade de tamanho metabólico (CMSUTM), digestibilidade aparente da matéria seca (DAMS) e consumo de matéria seca digestível por unidade de tamanho metabólico (CMSDUTM) das silagens dos híbridos de sorgo, em três estádios de maturação, estão apresentados na Tab. 2.
Tabela 2. Valores médios de consumo de matéria seca por unidade de tamanho metabólico (CMSUTM), em gramas por $\mathrm{kg}^{0,75}$ por dia, digestibilidade aparente da matéria seca (DAMS), em porcentagem, e consumo de matéria seca digestível por unidade de tamanho metabólico (CMSD-UTM), em gramas por kg ${ }^{0,75}$ por dia, das silagens de híbridos de sorgo em três estádios de maturação

\begin{tabular}{|c|c|c|c|}
\hline \multirow[b]{2}{*}{ Híbrido } & \multicolumn{3}{|c|}{ Parâmetros } \\
\hline & $\begin{array}{l}\text { CMS- } \\
\text { UTM }\end{array}$ & DAMS & CMSD-UTM \\
\hline & \multicolumn{3}{|c|}{ Leitoso } \\
\hline BRS 610 & 54,46 & 49,58 & 26,88 \\
\hline BR 700 & 52,53 & 56,02 & 29,26 \\
\hline \multirow[t]{2}{*}{ BRS 655} & 46,18 & 53,65 & 24,64 \\
\hline & \multicolumn{3}{|c|}{ Pastoso } \\
\hline BRS 610 & 56,73 & 56,67 & 32,19 \\
\hline BR 700 & 56,53 & 48,59 & 27,40 \\
\hline \multirow[t]{2}{*}{ BRS 655} & 45,90 & 51,76 & $23,85 \quad \mathrm{~B}$ \\
\hline & \multicolumn{3}{|c|}{ Farináceo } \\
\hline BRS 610 & 59,99 & 50,58 & 30,43 \\
\hline BR 700 & 55,12 & 51,45 & 28,42 \\
\hline BRS 655 & 51,20 & 48,53 & 24,72 \\
\hline
\end{tabular}

Médias seguidas por letras maiúsculas diferentes, na mesma coluna e no mesmo estádio de maturação, indicam diferença entre os híbridos, pelo teste SNK $(\mathrm{P}<0,05)$. Para o mesmo híbrido, não houve diferença entre estádios de maturação pelo teste SNK $(\mathrm{P}>0,05)$. CV CMS-UTM $=11,0 \% ;$ CV DAMS $=12,2 \% ; \mathrm{CV}$ CMSD-UTM $=14,6 \%$.

Não houve influência do estádio de maturação sobre o CMS-UTM para todos os híbridos (P>0,05). Comparando os materiais em um mesmo corte, no estádio pastoso, o BRS 655 apresentou menor valor $(45,90 \mathrm{~g} / \mathrm{PM})$ em relação aos demais híbridos $(\mathrm{P}<0,05)$, que foram semelhantes entre si $(\mathrm{P}>0,05)$. Já nos estádios leitoso e farináceo, não houve diferença estatística entre os híbridos. Pereira et al. (1993) encontraram valores médios de consumo de matéria seca de 61,3g/UTM/dia, 81,7g/UTM/dia e 74,6g/UTM/dia para sorgos de porte alto, médio e baixo, respectivamente. Martins et al. 
(2003a) obtiveram maior CMS para o BR 700 $(65,0 \mathrm{~g} / \mathrm{UTM} / \mathrm{dia})$ do que o observado no presente trabalho, enquanto Pires (2003) verificou menores CMS para sorgos forrageiros (entre $28,16$ e $33,54 \mathrm{~g} / \mathrm{UTM} / \mathrm{dia})$ do que para sorgos graníferos (entre 50,85 e $51,24 \mathrm{~g} / \mathrm{UTM} / \mathrm{dia}$ ). Souza et al. (2003) observaram valores entre $53,6 \mathrm{~g} / \mathrm{UTM} / \mathrm{dia}$ e $66,7 \mathrm{~g} / \mathrm{UTM} /$ dia para o CMS de silagens de sorgo por ovinos.

Para as DAMS, não houve variação entre híbridos, dentro do mesmo estádio de maturação, e entre idades de corte, para o mesmo híbrido $(\mathrm{P}>0,05)$. Os valores encontrados variaram de $48,5 \%$ a $56,7 \%$. O avanço do estádio de maturação não promoveu variação na DAMS, o que sugere que o acúmulo de amido nos grãos de sorgo compensou a queda na qualidade da parte vegetativa das plantas. Araújo et al. (2007) não observaram variações na digestibilidade in vitro da MS com o avanço da idade de corte, sendo as médias de $47,2 \%, 50,7 \%$ e $52,2 \%$ para os híbridos BR 700, BR 701 e MASSA 03, respectivamente, avaliados em cinco estádios de maturação. No trabalho de Pires et al. (2006), o efeito do estádio de maturação sobre a digestibilidade no sorgo apresentou comportamento variável para os diferentes híbridos avaliados.

Os três híbridos não apresentaram variação no CMSD-UTM com o avanço dos estádios de maturação $(\mathrm{P}>0,05)$. No estádio pastoso, o BRS 655 mostrou menor valor do que o BRS 610, enquanto o BR 700 apresentou valor intermediário e semelhante aos demais. O menor consumo de matéria seca digestível para o BRS 655 nesse estádio de maturação deve-se ao menor consumo de matéria seca, já que a digestibilidade aparente da matéria seca desse tratamento foi semelhante à dos demais híbridos $(\mathrm{P}>0,05)$. Nos outros estádios de maturação, não houve diferenças entre os CMSD-UTM dos híbridos avaliados $(\mathrm{P}>0,05)$. Pires (2003) obteve valores de DAMS para duas linhagens de sorgo granífero de $72,7 \%$ e $64,9 \%$, enquanto para o BR601 e BR 700, os valores foram $67,1 \%$ e $49,8 \%$, respectivamente. Os valores de CMSDUTM observados por esse autor para o BR 700 $(20,75 \mathrm{~g} / \mathrm{UTM} / \mathrm{dia})$ foi inferior ao verificado no presente trabalho para o mesmo híbrido $(27,40$ a 29,26g/UTM/dia). Entretanto, Martins et al. (2003a) verificaram valores mais altos de DAMS $(52,2 \%)$ e CMSD-UTM $(33,86 \mathrm{~g} / \mathrm{UTM} / \mathrm{dia})$ para o BR 700. Além do estádio de maturação, da proporção de grãos na massa ensilada e da qualidade da fibra, a digestibilidade da silagem de sorgo pode ser influenciada pela presença de taninos, que são conhecidamente inibidores da digestibilidade dos alimentos. Entretanto, no presente trabalho, não houve diferença $(\mathrm{P}>0,05)$ na DAMS entre o BRS 610, híbrido sem tanino, e o BRS 655 e BR700, ambos com tanino. Da mesma forma, Borges et al. (1997), ao avaliarem híbridos com e sem tanino, não observaram redução da digestibilidade in vitro da MS pela presença de taninos, ao contrário do que se esperava. Além disso, esses autores mostraram que a ensilagem provocou redução significativa nos teores de tanino, apesar de essa diminuição não ter resultado em aumento na digestibilidade in vitro da MS. Já Pires (2003) relatou menor digestibilidade aparente da MS para a silagem do híbrido BR 700, com tanino, em relação ao BR 601, sem tanino, evidenciando o efeito desse composto sobre a DAMS.

Na Tab. 3, estão apresentados os valores médios de consumo de proteína bruta por unidade de tamanho metabólico (CPB-UTM), digestibilidade aparente da proteína bruta (DAPB) e consumo de proteína digestível por unidade de tamanho metabólico das silagens dos híbridos de sorgo BRS 610, BR 700 e BRS 655 nos três estádios de maturação.

Para o CPB-UTM, os híbridos BRS 610 e BR 700 não mostraram diferenças entre os estádios de maturação (P>0,05). Já o BRS 655 apresentou maior CPB-UTM no estádio farináceo do que nos estádios leitoso e pastoso $(\mathrm{P}<0,05)$. Nos estádios leitoso e o pastoso, o híbrido BRS 655 obteve menores CPB-UTM $(\mathrm{P}<0,05)$ do que o BRS 610 e BR 700, que foram semelhantes entre si. O menor CPB-UTM para o BRS 655 parece estar relacionado ao menor CMS observado para sua silagem no estádio pastoso. Já no terceiro corte, não houve diferenças entre os híbridos avaliados com relação ao CPB-UTM $(\mathrm{P}>0,05)$. 
Tabela 3. Valores médios de consumo de proteína bruta por unidade de tamanho metabólico (CPB-UTM), em gramas por $\mathrm{kg}^{0,75}$ por dia, digestibilidade aparente da proteína bruta (DAPB), em porcentagem, e consumo de proteína digestível por unidade de tamanho metabólico (CPD-UTM), em gramas por $\mathrm{kg}^{0,75}$ por dia, de silagens de híbridos de sorgo em três estádios de maturação

\begin{tabular}{lccc}
\hline Híbrido & CPB-UTM & DAPB & CPD-UTM \\
\hline BRS 610 & Leitoso & $1,57 \mathrm{~A}$ \\
BR 700 & $3,81 \mathrm{~A}$ & 41,26 & $1,42 \mathrm{AB}$ \\
BRS 655 & $3,64 \mathrm{~A}$ & 39,56 & $1,03 \mathrm{~B}$ \\
\hline & $2,91 \mathrm{Bb}$ & $35,42 \mathrm{a}$ & \\
\hline BRS 610 & Pastoso & $1,74 \mathrm{~A}$ \\
BR 700 & 45,69A & $0,95 \mathrm{~B}$ \\
BRS 655 & $3,79 \mathrm{~A}$ & $27,25 \mathrm{~B}$ & $0,58 \mathrm{~B}$ \\
\hline & $3,54 \mathrm{~A}$ & $19,19 \mathrm{Bb}$ & \\
\hline BRS 610 & $2,76 \mathrm{Bb}$ & Farináceo & $1,50 \mathrm{~A}$ \\
BR 700 & & 38,78 & $1,07 \mathrm{~B}$ \\
BRS 655 & 3,83 & 31,10 & $0,90 \mathrm{~B}$ \\
\hline
\end{tabular}

Médias seguidas por letras maiúsculas diferentes, na mesma coluna e no mesmo estádio de maturação, indicam diferença entre os híbridos, pelo teste $\mathrm{SNK}(\mathrm{P}<0,05)$. Letras minúsculas diferentes na mesma coluna comparam o mesmo híbrido entre os estádios de maturação e indicam diferença pelo teste $\mathrm{SNK}(\mathrm{P}<0,05)$; CV PB-UTM = 10,9\%; $\mathrm{CV}$ DAPB $=28,4 \% ;$ CV CDP-UTM $=28,3 \%$.

Para os híbridos BRS 610 e BR 700 não ocorreram alterações DAPB com o avanço da idade de corte. Já a silagem do BRS 655 mostrou menor coeficiente de digestibilidade da proteína bruta no estádio pastoso e maior coeficiente no estádio leitoso, sendo o terceiro corte semelhante $(\mathrm{P}>0,05)$ aos dois primeiros. Comparando-se os híbridos dentro de um mesmo corte, nos estádios leitoso e farináceo, não houve diferenças entre os híbridos $(\mathrm{P}>0,05)$, mas, no estádio pastoso, o BRS 610 apresentou maior digestibilidade do que o BR 700 e o BRS $655(\mathrm{P}<0,05)$, que foram semelhantes entre si $(\mathrm{P}>0,05)$.

Com relação ao consumo de proteína digestível por unidade de tamanho metabólico (CPDUTM), no estádio leitoso a silagem do BRS 610 proporcionou maior valor do que a do BRS 655, sendo o BR 700 semelhante aos demais. Nos estádios pastoso e farináceo, o CPD-UTM obtido para o BRS 610 foi mais alto $(\mathrm{P}<0,05)$ que os dos BR 700 e BRS 655, que foram semelhantes entre si. Para todos os híbridos avaliados, não houve diferença $(\mathrm{P}<0,05)$ no CPD-UTM entre os estádios de maturação. Pereira et al. (1993), ao avaliarem a produtividade de três variedades de sorgo e o valor nutritivo de suas silagens, encontraram valores de consumo de proteína bruta variando de 5,4 a 7,5g/UTM/dia e digestibilidade aparente da proteína bruta entre $46,6 \%$ e $52,3 \%$ para sorgos de porte alto e baixo, respectivamente. Alguns dados de consumo de proteína digestível observados na literatura para silagens de sorgo, milho e milheto variaram de 0,76 a $3,25 \mathrm{~g} / \mathrm{UTM} / \mathrm{dia}, 4,24$ a $5,19 \mathrm{~g} / \mathrm{UTM} / \mathrm{dia}$ e 2,54 a 3,17g/UTM/dia, respectivamente (Pires, 2003; Freitas et al., 2002; Guimarães Júnior, 2006).

$\mathrm{Na}$ Tab. 4, estão apresentados os valores de nitrogênio ingerido, nitrogênio eliminado nas fezes, nitrogênio eliminado na urina e nitrogênio retido - diferença entre nitrogênio retido e excretado - e a relação entre o nitrogênio retido e o nitrogênio ingerido. Para a ingestão de nitrogênio (g/dia), excreção de nitrogênio fecal (g/dia) e excreção de nitrogênio urinário (g/dia), não foram observadas diferenças entre híbridos nos três períodos de colheita avaliados, assim como entre estádios de maturação para todos os híbridos $(\mathrm{P}>0,05)$. 
Tabela 4. Nitrogênio $(\mathrm{N})$ ingerido, $\mathrm{N}$ fecal, $\mathrm{N}$ urinário e balanço de nitrogênio ( $\mathrm{N}$ retido-UTM), em gramas por $\mathrm{kg}^{0,75}$ por dia, e relação $\mathrm{N}$ retido: $\mathrm{N}$ ingerido ( $\mathrm{N}$ ret: $\mathrm{N}$ ing), em porcentagem, de silagens de híbridos de sorgo em três estádios de maturação

\begin{tabular}{|c|c|c|c|c|c|c|}
\hline Híbrido & $\mathrm{N}$ ingerido & $\mathrm{N}$ fecal & $\mathrm{N}$ urinário & $\mathrm{N}$ retido-UTM & $\mathrm{N}$ ret: $\mathrm{N}$ in & $\lg (\%)$ \\
\hline & \multicolumn{6}{|c|}{ Leitoso } \\
\hline BRS 610 & 11,03 & 6,51 & 1,49 & 0,17 & 26,87 & \\
\hline BR 700 & 10,49 & 6,47 & 0,90 & 0,18 & 30,61 & \\
\hline \multirow[t]{2}{*}{ BRS 655} & 8,52 & 5,47 & 1,21 & 0,10 & 21,68 & $\mathrm{a}$ \\
\hline & \multicolumn{6}{|c|}{ Pastoso } \\
\hline BRS 610 & 10,62 & 5,73 & 1,38 & $0,20 \mathrm{~A}$ & 32,65 & A \\
\hline BR 700 & 10,13 & 7,34 & 0,97 & $0,10 \mathrm{~B}$ & 17,91 & $\mathrm{~B}$ \\
\hline \multirow[t]{2}{*}{ BRS 655} & 7,89 & 6,23 & 1,36 & $0,02 \mathrm{C}$ & 1,38 & $\mathrm{Cb}$ \\
\hline & \multicolumn{6}{|c|}{ Farináceo } \\
\hline BRS 610 & 11,31 & 6,77 & 1,10 & $0,18 \quad \mathrm{~A}$ & 28,65 & $\mathrm{~A}$ \\
\hline BR 700 & 9,88 & 6,79 & 1,21 & $0,11 \mathrm{AB}$ & 18,96 & $\mathrm{AB}$ \\
\hline BRS 655 & 9,91 & 7,19 & 1,78 & $0,05 \mathrm{~B}$ & 8,86 & $\mathrm{Bab}$ \\
\hline
\end{tabular}

Médias seguidas por letras maiúsculas diferentes, na mesma coluna e no mesmo estádio de maturação, indicam diferença entre os híbridos, pelo teste SNK $(\mathrm{P}<0,05)$. Letras minúsculas diferentes na mesma coluna comparam o mesmo híbrido entre os estádios de maturação e indicam diferença pelo teste $\mathrm{SNK}(\mathrm{P}<0,05)$; CV N ingerido= 20,6\%; $\mathrm{CV} \mathrm{N}$ fecal $=21,4 \% ; \mathrm{CV} N$ urinário $=38,9 \% ; \mathrm{CV} \mathrm{N}$ retido-UTM $=50,4 \% ; \mathrm{CV}$ Nret $/ \mathrm{Ning}=53,4 \%$.

Todos os tratamentos apresentaram balanço de nitrogênio levemente positivo, com variação entre $0,02 \mathrm{~g} / \mathrm{UTM} / \mathrm{dia}$ e $0,20 \mathrm{~g} / \mathrm{UTM} / \mathrm{dia}$. Foi observada superioridade para o BRS $610 \mathrm{em}$ relação ao BRS 655 nos estádios pastoso e farináceo. Martins et al. (2003a) obtiveram balanço de $\mathrm{N}$ entre 2,47 e 4,80g/dia, sendo que, para o BR 700 no estádio leitoso-pastoso, o valor obtido foi de 4,51g/dia, mais alto que o alcançado no presente trabalho. A recomendação clássica de que as dietas fornecidas a ruminantes devem apresentar um mínimo de 7\% de proteína bruta tem sido questionada. Trabalhos recentes mostraram que ovinos que receberam dietas com teores proteicos abaixo desse limite apresentaram balanço de nitrogênio positivo, o que sugere maior eficiência na reciclagem de nitrogênio quando os teores de proteína na dieta são baixos. No presente trabalho, foram obtidos balanços de nitrogênio positivos, apesar de os valores de proteína bruta das silagens avaliadas variarem de $6,1 \%$ a $6,9 \%$. Fato semelhante também foi observado por Mizubuti et al. (2002), que encontraram balanço de nitrogênio positivo para ovinos que receberam silagem de sorgo com teor de proteína de 5,1\%. Ambos os tratamentos proporcionaram balanços de nitrogênio positivo. Teixeira (2009) também relatou balanço de nitrogênio positivo $(2,38 \mathrm{~g} / \mathrm{dia})$ para o capimelefante verde cortado aos 112 dias $(5,0 \%$ de $\mathrm{PB})$.

Para a relação $\mathrm{N}$ retido: $\mathrm{N}$ ingerido no estádio leitoso, não houve diferença entre as silagens $(\mathrm{P}>0,05)$. Entretanto, no corte subsequente, o BRS 655 apresentou queda acentuada na retenção de nitrogênio em relação ao nitrogênio ingerido, de 21,7\% para 1,4\%. O híbrido BR 700 também mostrou queda numérica na relação $\mathrm{N}$ retido: $\mathrm{N}$ ingerido entre os estádios leitoso e pastoso, de 30,6\% para 17,9\%, apesar de essa variação não ser significativa estatisticamente. Para o BRS 610, a relação $\mathrm{N}$ retido: $\mathrm{N}$ ingerido variou apenas de $26,9 \%$ a $32,6 \%$. Assim, no estádio pastoso, o BRS 610 apresentou maior valor para a razão entre nitrogênio retido e ingerido do que o BR 700, que, por sua vez, foi superior ao BRS 655. No estádio farináceo, o BRS 610 apresentou maior valor do que o BRS 655, enquanto o BR 700 mostrou-se intermediário e semelhante aos demais híbridos.

Na Tab. 5, são apresentados os consumos de fibra em detergente neutro por unidade de tamanho metabólico, digestibilidade da FDN e consumo de FDN digestível. 
Tabela 5. Valores médios de consumo de fibra em detergente neutro por unidade de tamanho metabólico (CFDN-UTM), em gramas por $\mathrm{kg}^{0,75}$ por dia, digestibilidade da fibra em detergente neutro (DAFDN), em porcentagem, e consumo de fibra em detergente neutro digestível por unidade de tamanho metabólico (CFDND-UTM), em gramas por $\mathrm{kg}^{0,75}$ por dia, de silagens de híbridos de sorgo em três estádios de maturação

\begin{tabular}{|c|c|c|c|}
\hline Híbrido & CFDN-UTM & DFDN & CFDND-UTM \\
\hline \multicolumn{4}{|c|}{ Leitoso } \\
\hline BRS 610 & 33,46 & $41,41 \mathrm{ab}$ & $13,74 \mathrm{ab}$ \\
\hline BR 700 & 31,66 & 45,51 & 14,24 \\
\hline BRS 655 & 29,21 & 46,65 & 13,54 \\
\hline \multicolumn{4}{|c|}{ Pastoso } \\
\hline BRS 610 & 34,00 & 48,88 a & 16,67 Aa \\
\hline BR 700 & 34,39 & 38,60 & $13,16 \mathrm{~B}$ \\
\hline BRS 655 & 29,04 & 43,34 & $12,58 \quad \mathrm{~B}$ \\
\hline \multicolumn{4}{|c|}{ Farináceo } \\
\hline BRS 610 & 32,45 & $35,03 \quad b$ & 11,49 \\
\hline BR 700 & 34,72 & 41,89 & 14,58 \\
\hline BRS 655 & 31,29 & 39,49 & 12,22 \\
\hline
\end{tabular}

Médias seguidas por letras maiúsculas diferentes, na mesma coluna e no mesmo estádio de maturação, indicam diferença entre os híbridos, pelo teste SNK $(\mathrm{P}<0,05)$. Letras minúsculas diferentes na mesma coluna comparam o mesmo híbrido entre os estádios de maturação, sendo que letras minúsculas diferentes indicam diferença pelo teste SNK $(\mathrm{P}<0,05)$; CV FDN-UTM=11,4\%; CV DFDN = 18,6\%; CV CFDND-UTM=18,7\%.

Os valores de consumo de FDN por unidade de tamanho metabólico não variaram entre híbridos e entre estádios de maturação $(\mathrm{P}>0,05)$. As digestibilidades da FDN (DFDN) foram semelhantes entre os híbridos para todos os estádios de maturação. Os híbridos BR 700 e BRS 655 não mostraram variação significativa na DFDN entre os pontos de corte. Já o BRS 610 apresentou DFDN mais alta no estádio pastoso em relação ao farináceo, enquanto a do estádio leitoso foi semelhante à dos outros dois cortes.

O consumo de FDN digestível, em gramas por $\mathrm{kg}$ de unidade de tamanho metabólico (CDFNDUTM), foi mais elevado no BRS 610 no estádio pastoso em relação aos demais híbridos. Nos estádios leitoso e farináceo, não houve diferença significativa $(\mathrm{P}>0,05)$ entre as silagens. Assim como foi observado para digestibilidade da FDN, o CFDND-UTM do híbrido BRS 610 foi maior $(\mathrm{P}<0,05)$ no estádio pastoso $(16,67 \mathrm{~g} / \mathrm{UTM} / \mathrm{dia})$ em relação ao farináceo $(11,49 \mathrm{~g} / \mathrm{UTM} / \mathrm{dia})$.

$\mathrm{Na}$ Tab. 6, são apresentados os consumos de fibra em detergente ácido (FDA), digestibilidade da FDA e consumo de FDA digestível.
Com relação ao consumo de FDA por unidade de tamanho metabólico, nos estádios leitoso e farináceo, os híbridos mostraram-se semelhantes entre si $(\mathrm{P}>0,05)$, mas, no estádio pastoso, o BRS 655 apresentou menor valor $(\mathrm{P}<0,05)$ do que os demais, que foram semelhantes entre si. Para a digestibilidade da FDA, não houve oscilação significativa entre os tratamentos $(\mathrm{P}>0,05)$. Considerando-se o consumo de FDA digestível por unidade de tamanho metabólico (CFDADUTM), no primeiro e segundo cortes não se observou diferença significativa entre os híbridos, mas no estádio pastoso o BRS 610 foi superior ao BRS 655, enquanto o BR 700 mostrou-se semelhante a ambos. Assim como foi observado para o consumo de FDN digestível por unidade de tamanho metabólico, o CFDADUTM do híbrido BRS 610 foi maior $(\mathrm{P}<0,05)$ no estádio pastoso $(8,95 \mathrm{~g} / \mathrm{UTM} / \mathrm{dia})$ em relação ao farináceo $(5,77 \mathrm{~g} / \mathrm{UTM} / \mathrm{dia})$, enquanto o estádio leitoso mostrou-se semelhante aos outros dois cortes $(8,07 \mathrm{~g} / \mathrm{UTM} / \mathrm{dia})$. 
Tabela 6. Valores médios de consumo de fibra em detergente ácido por unidade de tamanho metabólico (CFDA-UTM), em gramas por $\mathrm{kg}^{0,75}$ por dia, digestibilidade da fibra em detergente ácido (DFDA), em porcentagem, e consumo de fibra em detergente ácido digestível por unidade de tamanho metabólico (CFDAD-UTM), em gramas por $\mathrm{kg}^{0,75}$ por dia, de silagens de híbridos de sorgo de em três estádios de maturação

\begin{tabular}{|c|c|c|c|}
\hline Híbrido & CFDA-UTM & DFDA & CFDAD-UTM \\
\hline \multicolumn{4}{|c|}{ Leitoso } \\
\hline BRS 610 & 19,38 & 41,64 & $8,07 \quad a b$ \\
\hline BR 700 & 16,31 & 36,50 & 5,88 \\
\hline BRS 655 & 16,36 & 38,76 & 6,36 \\
\hline \multicolumn{4}{|c|}{ Pastoso } \\
\hline BRS 610 & $19,49 \quad \mathrm{~A}$ & 45,52 & 8,95 Аа \\
\hline BR 700 & $18,92 \mathrm{~A}$ & 34,45 & $6,48 \quad \mathrm{AB}$ \\
\hline BRS 655 & $15,34 \quad$ B & 33,75 & 5,29 B \\
\hline \multicolumn{4}{|c|}{ Farináceo } \\
\hline BRS 610 & 18,16 & 31,43 & $5,77 \quad b$ \\
\hline BR 700 & 18,74 & 34,98 & 6,58 \\
\hline BRS 655 & 17,02 & 32,75 & 5,48 \\
\hline
\end{tabular}

Médias seguidas por letras maiúsculas diferentes, na mesma coluna e no mesmo estádio de maturação, indicam diferença entre os híbridos, pelo teste $\mathrm{SNK}(\mathrm{P}<0,05)$. Letras minúsculas diferentes na mesma coluna comparam o mesmo híbrido entre os estádios de maturação, e indicam diferença pelo teste $\mathrm{SNK}(\mathrm{P}<0,05)$; CV FDA-UTM= $13,5 \% ;$ CV DFDA $=29,6 \% ;$ CV CFDAD-UTM $=30,4 \%$.

Pires (2003) observou consumo de FDN e FDA variando, respectivamente, de 14,27g/UTM/dia e $8,01 \mathrm{~g} / \mathrm{UTM} / \mathrm{dia}$ (BR 700) a 24,47g/UTM/dia e $13,54 \mathrm{~g} / \mathrm{UTM} / \mathrm{dia}$ (linhagem granífera), valores mais baixos que os obtidos no presente experimento. Os valores de digestibilidade da FDN e FDA observados pelo autor para o híbrido BR 700 foram de $40,9 \%$ e $39,3 \%$, respectivamente. Martins et al. (2003b) obtiveram variação do consumo e da digestibilidade de FDN de 34,0g/UTM/dia a $40,59 \mathrm{~g} / \mathrm{UTM} / \mathrm{dia}$ e de $32,8 \%$ a $54,9 \%$, respectivamente, e variação do consumo e da digestibilidade da FDA de 24,18g/UTM/dia a $35,15 \mathrm{~g} / \mathrm{UTM} / \mathrm{dia}$, e de $39,6 \%$ a $53,6 \%$, respectivamente. Esses valores foram mais altos que os observados no presente experimento. Bezerra et al. (1993), ao analisarem o valor nutricional de silagens de rebrotas de sorgo, obtiveram valor médio de digestibilidade aparente da FDN e da FDA de 60,9\% e 40,2\%, respectivamente. A diferença frente aos dados da literatura pode estar relacionada ao tipo de sorgo utilizado, estádio de maturação na colheita, composição química das silagens, condições climáticas, relação folha:colmo:panícula das plantas, variações entre os animais experimentais, entre outros.

\section{CONCLUSÕES}

Os híbridos BR 700 e BRS 655 devem ser colhidos no estádio leitoso a fim de garantir a obtenção de silagens com melhor balanço de nitrogênio. A silagem do híbrido BRS 610 no estádio pastoso foi a de melhor resultado quanto à quantidade de nitrogênio retida pelos animais, portanto ela é recomendável. Todos os tratamentos apresentaram balanço de nitrogênio positivo, sugerindo que, para dietas com baixo teor de proteína, há aumento da capacidade de reciclagem do nitrogênio pelos ruminantes. Não houve influência dos taninos sobre $\mathrm{O}$ aproveitamento da fibra das silagens. 


\section{REFERÊNCIAS BIBLIOGRÁFICAS}

ARAUJO, V.L., RODRIGUEZ, N.M.; GONÇALVES, L.C. et al. Qualidade das silagens de três híbridos de sorgo ensilados em cinco diferentes estádios de maturação. Arq. Bras. Med. Vet. Zootec., v.59, p.168174, 2007

BEZERRA, E.S.; VON TIESENHAUSEN, I.M.E.V.; OLIVEIRA, A.I. et al. Valor nutricional das silagens de milho, milho consorciado com sorgo e rebrotas de sorgo. Rev. Bras. Zootec., v.22, p. 1044-1054, 1993.

BORGES, A.L.C.C.; GONÇALVES, L.C.; RODRÍGUEZ, N. M. et al. Silagem de sorgo de porte alto com diferentes teores de taninos e suculência do colmo. I. Nitrogênio amoniacal, $\mathrm{pH}$ e perdas de matéria seca. Arq. Bras. Med. Vet. Zootec., v. 49, p.719-732, 1997.

FREITAS, G.A.R.; GONÇALVES, L.C.; COELHO, S.G. et al. Consumo e digestibilidade aparente das frações fibrosas das silagens de cinco genótipos de milho (Zea mays L.) em ovinos. In: REUNIÃO ANUAL DA SOCIEDADE BRASILEIRA DE ZOOTECNIA, 39., 2002, Recife. Anais... Recife: SBZ, 2002. CD-ROM.

GUIMARÃES Jr., R. Avaliação nutricional de silagens de milheto [Pennisetum glaucum (l.). R. Br.]. 2006. 90f. Tese (Doutorado) - Escola de Veterinária, Universidade Federal de Minas Gerais, Belo Horizonte, MG.

MARTINS, R.G.R.; GONÇALVES, L.C.; RODRIGUES, J.A.S. et al Consumo e digestibilidade aparente da matéria seca, da proteína bruta e da energia de silagens de quatro genótipos de sorgo (Sorghum bicolor (L.) Moench) por ovinos. Arq. Bras. Med. Vet. Zootec., v.55, p.341-345, 2003 a.

MARTINS, R.G.R.; GONÇALVES, L.C.; RODRIGUES, J.A.S. et al. Consumo e digestibilidade aparente das frações fibrosas de silagens de quatro genótipos de sorgo (Sorghum bicolor (L.) Moench) por ovinos. Arq. Bras. Med. Vet. Zootec., v.55, p.347350, 2003b.

MAYNARD, L.A.; LOOSLI, B.S.; HINTZ, H.F. et al. Nutrição animal. 3.ed. Rio de Janeiro: Freitas Bastos, 1984. $726 \mathrm{p}$

MIZUBUTI, I.Y.; RIBEIRO, E.L.A.; ROCHA, M.A. et al. Consumo e digestibilidade aparente das silagens de milho, sorgo e girassol. Rev. Bras. Zootec., v.31, p.267-272, 2002.

MOLINA, L.R.; RODRIGUEZ, N.M.; GONÇALVES, L.C. et al. Degradabilidade in situ da matéria seca e da proteína bruta das silagens de seis genótipos de sorgo (Sorghum bicolor (L.) Moench), com e sem tanino no grão, ensilados no estádio de grão farináceo. Braz. $J$. Vet. Res. Anim. Sci., v.39, p.233-237, 2002.
OFFICIAL methods of analysis. 17.ed. Gaithersburg: AOAC, 2000. 2000p.

PEDREIRA, M.S.; REIS, R.A.; BERCHIELI, T.T. et $a l$. Características agronômicas e composição química de oito híbridos de sorgo (Sorghum bicolor (L.) Moench). Rev. Bras. Zootec., v.32, p.1083-1092, 2003.

PEREIRA, O.G.; OBEID, J.A.; GOMIDE, J.A.: QUEIROZ, A.C. Produtividade de uma variedade de milho (Zea mays L.) e de três variedades de sorgo (Sorghum bicolor L. Moench) e o valor nutritivo de suas silagens. Rev. Bras. Zootec., v.22, p.31-38, 1993.

PIRES, D.A.A. Consumo e digestibilidade aparente em ovinos de silagens de sorgo com e sem taninos nos grãos. 2003. 53f. Dissertação (Mestrado) - Escola de Veterinária, Universidade Federal de Minas Gerais, Belo Horizonte.

PIRES, D.A.A.; GUIMARAES Jr., R., JAYME, D.G. et al. Qualidade e valor nutritivo das silagens de três híbridos de sorgo (Sorghum bicolor (L.) Moench) colhidos em diferentes estádios de maturação. Rev. Bras. Milho Sorgo, v.5, p.241-256, 2006

RUSSEL, B.J.; O' CONNOR, J.D.; FOX; D.J., et al. A net carbohydrate and protein system for evaluation cattles diets: ruminal fermentation. J. Anim. Sci., v.70, p.1955-1963, 1992.

SISTEMA para análises estatísticas - SAEG. Versão 9.1. Viçosa:UFV, 2007.

SOUZA, V.G.; PEREIRA, O.G.; MORAES, S.A. et al. Valor nutritivo de silagens de sorgo. Arq. Bras. Med. Vet. Zootec., v.32, p.347-350, 2003.

TEIXEIRA, A.M. Consumo voluntário $e$ digestibilidade aparente do capim-elefante verde em diferentes idades de corte em ovinos. 2009. 30f. Tese (Mestrado) - Escola de Veterinária, Universidade Federal de Minas Gerais, Belo Horizonte.

VAN SOEST, P.J.; ROBERTSON, J.B., LEWIS, B.A. Methods for dietary fiber and nonstarch polysaccaridies in relation to animal nutrition. J. Dairy Sci, v.74, p.3583-3597, 1991.

VAN SOEST, P.J. Nutritional ecology of the ruminant. 2.ed. Ithaca. NY: New York: Cornell University, 1994. 476p. 